\title{
Study Treatment Causality
}

National Cancer Institute

\section{Source}

National Cancer Institute. Study Treatment Causality. NCI Thesaurus. Code C103163.

The principle that a relationship exists between a study treatment (cause) and the occurrence of an event (effect). 